\title{
Caminhos de um "espetáculo" acadêmico. E algumas peripécias...
}

\author{
Zilma Adélia Soares Lopes ${ }^{I}$
}

Resenha recebida em 09/03/2015 e aprovada em 13/08/2015.

A grande onda vai te pegar. Marketing, espetáculo e ciberespaço na Bola de Neve Church $^{I I}$ alcançou um público leitor para além do acadêmico. Houve uma tentativa, por parte da instituição religiosa em estudo, de inviabilizar o lançamento da obra, promovendo um espetáculo que circulou na mídia e no ciberespaço, especialmente nas redes sociais, e proporcionou ao livro um excelente marketing com a temática da censura. Entretanto, seria muito precário atribuir unicamente a essa estratégia mal calculada da Bola de Neve Church (BDN) o sucesso obtido. A obra de Eduardo Meinberg de Albuquerque Maranhão Filho tem seus próprios méritos.

O vasto currículo do autor, já de início, garante ao leitor o compromisso dele com este trabalho de fôlego: é doutorando em História pela Universidade de São Paulo (USP), mestre em História pela Universidade do Estado de Santa Catarina (UDESC), especialista em Marketing e Comunicação Social pela Cásper Líbero e ainda é editor de revistas brasileiras de referência nos estudos de religião. Essas credenciais lhe conferem autoridade no assunto tratado no livro, uma versão ampliada de sua dissertação de mestrado, defendida em 2010. Sua entrada em campo se deu no ano de 2005, na sede da Bola de Neve Church (BDN) em Florianópolis, até a data de defesa da dissertação. A partir de 2012, retomou sua observação participante/participação observante - como o próprio autor frisa - numa unidade da Bola de Neve em Florianópolis, a fim de "acompanhar inovações e continuidades". Em 2013, ano da publicação do livro pela Fonte Editorial, reforçou as observações etnográficas digitais pelas redes sociais, pois já as empreendia há algum tempo: até 2008, por exemplo, foi administrador da comunidade da chamada "BDN Floripa" no Orkut, um site de relacionamentos.

Assim, de inspiração etnográfica, A grande onda vai te pegar... tem como objetivo identificar os desdobramentos das estratégias de "marketing de guerra "santa", conceito elaborado e instrumentalizado pelo autor, uma adaptação para o mercado religioso do conceito de marketing de guerra, concebido por Al Ries e Jack Trout. A concepção elaborada por Maranhão Filho representa "a criação, apropriação e ressignificação de estratégias de gerenciamento militar e/ou empresarial, efetuadas pelas agências religiosas" III . Em geral, o autor busca apontar as possíveis relações entre mercado, espetáculo e fé. Assim, o uso de conceitos e termos provenientes de teorias de Marketing foram de extrema relevância na formulação do "marketing de guerra "santa", para apontar um contexto de concorrência e mercadorização religiosa na contemporaneidade, enfatizado pelo uso recorrente do termo "agência religiosa", em lugar de "instituição eclesiástica/religiosa" ou "igreja". Suas conclusões, ou "considerações inconclusivas", são apresentadas ao longo dos capítulos.

Vale salientar que esse conceito elaborado pelo autor é enfatizado como em constante movimento, isto é, sempre "em trânsito", deslocando-se de acordo com as expectativas e desejos dos fieis. Daí, como explica, a razão de muitas vezes determinadas agências se apropriarem de alguns elementos de outras expressões religiosas para conquistar a preferência do "fiel-consumidor". Por isso, algumas delas, como a BDN, se apropriam e ressignificam

Cadernos do Tempo Presente, n. 22, dez.2015/jan. 2016, p. 86-90|http://www.seer.ufs.br/index.php/tempo 
termos beligerantes, como "marchar", "guerrear" e "conquistar", com o objetivo de promoverem-se e consolidarem-se no campo religioso. Mais outros dois sentidos envolvem-se a essa "guerra santa", segundo o autor: o de batalha espiritual, um dos pilares da teologia neopentecostal; e o marketing da intolerância, em que uma agência investe violentamente contra outra agência ou expressão religiosa. Sobre este sentido, convém apontar ainda que a intolerância da BDN se apresentou de maneira nítida nas iniciativas de censura ao lançamento do livro de Maranhão Filho, ironicamente, no Simpósio de Diversidades e (In) Tolerâncias Religiosas, promovido pela Associação Brasileira de História das Religiões (ABHR), na Universidade de São Paulo (USP), em fins de outubro de 2013. Além disto, o autor foi alvo de cyberbullying - não necessariamente por parte da BDN, conforme declarou o autor publicamente, mas por pessoas diversas, cuja relação com a agência não se pode afirmar -, após a mídia apontar seus holofotes sobre a ação da BDN. Este caso culminou em processo na Delegacia de Crimes Raciais e Delitos de Intolerância (DECRADI), vale salientar.

Após frisar a incorporação de termos beligerantes pela BDN, num relevante momento de explanação dos conceitos utilizados na obra, Maranhão Filho argumenta que qualquer religião pode se utilizar de estratégias de marketing, porém, dentre as agências religiosas cristãs, as neopentecostais são as que mais se instrumentalizam delas, tendo a Igreja Universal do Reino de Deus (IURD) como modelo. Por isso, a título de comparação explicativa, o autor recorrentemente se refere a características mercadológicas desta agência para explicar estratégias da Bola de Neve Church - cujas particularidades são majoritariamente neopentecostais, conforme o autor -, na qual as teologias da prosperidade, domínio e batalha espiritual lhes são notadamente características.

Diante dessas classificações e caracterizações, Maranhão Filho levanta uma relevante discussão em torno do que entende ocorrer na BDN: um "derretimento identitário", uma provisoriedade e transitoriedade da identidade. Amparado na concepção de "entre-lugares", de Homi K. Bhabha, o autor caracteriza a identidade da BDN por um aparente paradoxo entre um discurso flexível em relação a usos e costumes, nomeado como discurso derretido; e outro um tanto rígido, chamado de "congelado", que reflete variados policiamentos frente "à sexualidade, afetividade e papeis de gênero, nas apropriações e significações em relação ao corpo e ao esporte e no uso das teologias do domínio, cura/libertação, saúde perfeita, prosperidade e batalha espiritual" IV. Em se tratando de uma possível "identidade institucional", Maranhão Filho aponta ser possível caracterizá-la pelo "trânsito e/ou bricolagem entre mídia e espetáculo", devido a sua intensa presença no ciberespaço. Visto que se preocupa em não adotar dicotomias como "demandas espirituais/comerciais, igreja/empresa", para o autor, é possível que a BDN esteja "entre estes dois lugares e seja simultaneamente as duas coisas: tenha um pouco de igreja e um tanto de firma, e interesses financeiros e religiosos coabitem" $\mathrm{V}$.

O enfoque, a partir de então, recai sobre o que chama de "identidade derretida", fluida da Bola de Neve Church. O surfe, especialmente, como marca inicial, originária, que gira em torno do mito fundador da agência, é um dos primeiros elementos analisados nesse sentido. Para Maranhão Filho, a permanência desse esporte como prática identitária da BDN está envolvida em contínuas tensões e negociações, visto que a agência tem alcançado um público maior e mais heterogêneo, atendendo novos nichos mercadológicos, cujo público pratica outros tipos de esporte. Sendo assim, para garantir a unidade ao passo em que atende às novas demandas, a instituição elabora um discurso de "identidade comum", por meio de sua estrutura organizativa: os ministérios ("agenciadores da consolidação da BDN") e as células ("elemento de coesão identitária"). 


\section{CAMINHOS DE UM “ESPETÁCULO” ACADÊMICO. E ALGUMAS PERIPÉCIAS...}

\section{ZILMA ADÉLIA SOARES LOPES}

No terceiro grande momento da obra, o autor se dedica a analisar os dois tipos de discurso da BDN: o "derretido" e o "congelado". Para ele, o discurso derretido é marcado por coloquialidade linguística e comportamental - tanto por parte dos fieis como da liderança -, assim como a valorização estética do corpo - especialmente através de tendências da moda que remetam a práticas esportivas e de acordo com os diferentes contextos locais em que se encontram as unidades da agência. O discurso congelado se destaca através da teologia considerada fundamentalista, de batalha e domínio espiritual, prosperidade, saúde perfeita, como também por meio da questão dos papeis de gênero e da sexualidade. Cabe ainda destacar que Maranhão Filho analisa, rapidamente, o discurso em relação à participação política pela via partidária, indicando que, através da doutrina do domínio santo, a BDN se alinha ao posicionamento de outras agências religiosas que pensam ser possível realizar um tipo de neocristandade na sociedade brasileira.

A seção seguinte é desenvolvida pelo autor de modo a problematizar a relação notadamente existente entre processo de produção do espetáculo na esfera religiosa, especificamente neste estudo, na BDN, e recursos midiáticos. Maranhão Filho, no entanto, ressalta que a análise da "espetacularização da fé" deve levar em consideração ainda a existência de devoções, de manifestações da religiosidade, da subjetividade dos fieis, de modo a ir-se além de uma posição interpretativa puramente mercadológica das agências religiosas. Adiante, o autor destaca e discorre sobre as diversas formas de midiatização da BDN: espetacularização patrimonial - por exemplo, as fachadas dos templos, que antes de virem a ser espaços religiosos, no caso da BDN, anteriormente eram casas de shows, conforme aponta Maranhão Filho; como também bens tangíveis - a partir dos quais discute a questão da autoespetacularização, introduzindo toda uma discussão a respeito do que se entende por corpo na contemporaneidade, especificamente na esfera religiosa. Analisa ainda as estratégias comerciais dos produtos da agência, propagandizados, sobretudo no ciberespaço. Destaca que uma das mercadorias mais espetacularizadas e midiatizadas pela BDN é a chamada canção gospel e, a partir daí, realiza toda uma apreciação a respeito das especificidades musicais desse gênero musical no Brasil, atentando especificamente para a canção "Caia Babilônia", uma espécie de hino dessa agência, de acordo com o autor. $\mathrm{O}$ esporte também é destacado por Maranhão Filho como uma estratégia de atração, tal qual a música, como o caso do ministério Bola Running, que analisa detalhadamente.

Construir uma compreensão a respeito da importância dos recursos proporcionados pelo ciberespaço para a agência religiosa em estudo é o próximo passo de Maranhão Filho. Argumenta sobre a relação mídia/religião e, em seguida, explica a distinção entre religiões/religiosidades no e $d o$ ciberespaço. Reflete a respeito do que pode ser uma imbricação entre máquinas (computadores) e pessoas. Destaca o caráter fluido e volátil tanto do ciberespaço quanto da BDN e seu site, ao realizar uma análise contextual do portal cibernético da agência. Discute o constante uso de anglicismos na BDN e a forte participação de personalidades da teologia neopentecostal dos Estados Unidos como preletores em seminários promovidos por ela. Estes aspectos são tomados como demonstradores de uma estratégia de marketing de guerra santa em adaptação ao cotidiano do público/fiel, familiarizado com produtos e mercadorias representados através do idioma inglês, por conta de seu perfil socioeconômico (classe média alta), segundo o autor. Maranhão Filho, enfim, faz uma descrição histórica da radiodifusão evangélica no Brasil para analisar os canais virtuais de rádio da agência: o Bola Radio Worship e o Bola Radio Extreme. Suas linguagens e estilos musicais incluídos nos repertórios, entre outros aspectos, estão compreendidos em um dos diferenciais da BDN em relação a outras agências religiosas: o uso do ciberespaço para a difusão de seus produtos e mercadorias de fé.

Cadernos do Tempo Presente, n. 22, dez.2015/jan. 2016, p. 86-90|http://www.seer.ufs.br/index.php/tempo 
O olhar de Maranhão Filho sobre a BDN parte de uma visão contemporânea de mundo, fazendo desse trabalho um exercício, por assim dizer, de História do Tempo Presente, e não simplesmente pelo fato de o recorte temporal estar em proximidade com a atualidade em que vivencia suas observações. Por isso, preocupa-se continuamente no texto em apontar a precariedade dos termos que utiliza, apontando-os como sob rasura, baseado nas argumentações de Stuart Hall, pelo fato de não darem conta das diversas especificidades do objeto/sujeito de estudo, devido à fluidez do tempo moderno. É neste sentido que se instrumentaliza das teorizações de intelectuais como Bhabha, Garcia-Canclini e Zigmunt Baumann, por exemplo.

O quadro teórico adotado neste trabalho abarca teóricos de diferentes correntes de pensamento: por exemplo, recorrentemente se baseia nas argumentações de Pierre Bourdieu enquanto noutros momentos, nas de Michel Foucault, de modo que as teorias lhe são tomadas como instrumentos úteis, de acordo com as exigências específicas dos aspectos observados. Isso lhe proporciona um aporte teórico-metodológico extremamente rico e coerente com a proposta do trabalho, como também coincide com a "natureza" (se assim pudermos afirmar) flexível de seu sujeito/objeto de estudo. Maranhão Filho ainda instrumentaliza-se bastante dos escritos de Leonildo Silveira Campos e Magali do Nascimento Cunha, os quais trabalham as questões de mercadorização, marketing e midiatização, em igrejas brasileiras consideradas neopentecostais, e dos de Stewart Hoover, que analisa as relações entre religião e mídia.

Assim, com um estilo de escrita claro, preciso e coerente, de linguagem interessante e numa forma lógica e sistematizada, estruturada com equilíbrio nas partes do texto, o estudo etnográfico empreendido por Maranhão Filho, ora publicado nesse livro, apresenta originalidade, principalmente no que tange ao estudo das estratégias de marketing religioso ao conceituar o chamado "marketing de guerra 'santa", dentre outros aspectos. Trata-se de uma obra recomendável não apenas a especialistas em marketing religioso ou religiosidade no ciberespaço, mas também a estudantes interessados na compreensão dos discursos e práticas de instituições neopentecostais - especialmente das que têm interesse específico no público jovem, como a $\mathrm{BDN}$-, e ao grande público, pois não são necessários conhecimentos acadêmicos profundos para que seja possível ao leitor a compreensão das análises empreendidas pelo autor: Maranhão Filho as desenvolve com muita clareza, didática e distinção.

\section{Notas}

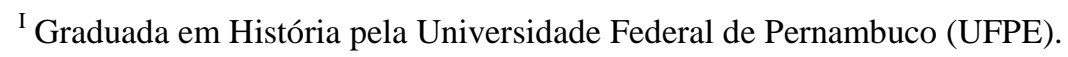

II MARANHÃO $\mathrm{F}^{\mathrm{o}}$, Eduardo Meinberg de Albuquerque. A grande onda vai te pegar. Marketing, espetáculo e ciberespaço na Bola de Neve Church. São Paulo: Fonte Editorial, 2013.

III Ibid.

IV Ibid.

V Ibid. 
CAMINHOS DE UM “ESPETÁCULO” ACADÊMICO. E ALGUMAS PERIPÉCIAS...

ZILMA ADÉLIA SOARES LOPES

\section{Referência Bibliográfica}

MARANHÃO $\mathrm{F}^{\mathbf{o}}$, Eduardo Meinberg de Albuquerque. A grande onda vai te pegar. Marketing, espetáculo e ciberespaço na Bola de Neve Church. São Paulo: Fonte Editorial, 2013. ISBN: 978-85-66480-66-5. 